\title{
Entrevista com o grupo teatral Alcolu é aqui
}

Cláudia Rocha da Silva ${ }^{1}$

Rosana Baú Rabello²

DOI 10.11606/issn.1981-7169.crioula.2017.132172

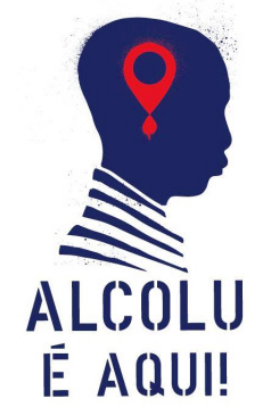

Identidade visual (Edson lkê)

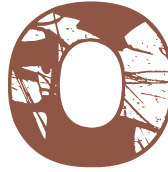

grupo teatral Alcolu é aqui foi constituído no início de 2016, na Vila Formosa, zona leste da capital de São Paulo, tendo como proposta a criação de um projeto que abordasse o racismo, com foco no genocídio da população negra. Utilizaram o teatro, a performance e a internet como potencializadores dessa discussão.

Sensíveis à problemática da violência racial que atinge, especialmente, os jovens, e pensando em como contribuir

1 Professora da Universidade do Estado da Bahia (UNEB). Doutoranda dos Estudos Comparados de Literaturas de Língua Portuguesa, da Usp. Mestre em educação e Contemporaneidade (PPGEduc/UNEB). E-mail: kaurssilva@gmail.com

2 Doutoranda dos Estudos Comparados de Literaturas de Língua Portuguesa, da USP. E-mail: rosanabau@gmail.com 
para reverter esse quadro, o grupo fez a opção política de se aproximar da população, no intuito de discutir o racismo, téte a téte. Essa aproximação é realizada através de oficinas teatrais gratuitas, performances urbanas, leituras dramáticas e de uma plataforma on line onde é possível registrar a ocorrência de situações de racismo, vivenciadas pelas próprias vítimas, em São Paulo.

A escolha pelo teatro não foi por acaso, pois o grupo considera "o fazer teatral um ato político" dada a sua "capacidade de despertar sentimentos nas pessoas, de ser um estímulo para promover mudanças políticas e sociais."

A entrevista, ora apresentada, permitirá aos leitores da Revista Crioula conhecer um pouco mais da experiência, dos projetos futuros, e da própria concepção do grupo Alcolu é aqui, cuja atuação tem sido um grande espetáculo.

Crioula: Quando e como o grupo foi constituído, como surgiu a proposta do projeto de investigação teatral Alcolu é aqui e por que relacioná-la ao caso de Alcolu, nos Estados Unidos?

Alcolu: O grupo foi constituído no início de 2016, quando nós (Bruna Menezes, Gabriel Cândido, Leonardo de Sá e Mariana Arantes) nos organizamos ao redor da elaboração de um projeto que usasse o teatro, a performance e a internet para discutir racismo no Brasil com foco no genocídio da população negra. A semente do "Alcolu é aqui!", no entanto, é anterior. Em dezembro de 2014, a Folha de S. Paulo publicou a seguinte notícia: "Execução de adolescente negro é considerada irregular 70 anos depois". O conteúdo da matéria expunha o caso de George Stinney Jr., jovem negro que, em 1944, foi condenado 
à morte aos 14 anos de idade, na segregada cidade de Alcolu (EUA), após ter sido acusado de ter assassinado duas garotas brancas. Stinney entrou para história como a mais jovem vítima da pena de morte na América. Anos depois, uma juíza da Carolina do Sul, reabriu o processo de Stinney e detectou uma série de irregularidades tanto em sua acusação quanto em toda a transição do processo legal, chegando à conclusão de que não havia provas suficientes para que ele tenha sido enviado à cadeira elétrica. Stinney foi inocentado 60 anos depois de sua morte. Esta notícia foi o disparador para que o Leonardo, que na ocasião era aprendiz do curso regular de Dramaturgia da SP Escola de Teatro, escrevesse o texto "O Estado Contra George em Alcolu". Esse texto foi fonte para a realização de três leituras dramáticas abertas ao público: a primeira numa atividade da própria escola, chamada "SP Dramaturgias"; a segunda durante o Festival Satyrianas, que acontece anualmente na Praça Roosevelt; e a terceira dentro da ocupação cultural da Escola Estadual Antônio Firmino Proença, no bairro da Mooca no final de 2015, quando os estudantes secundaristas ocuparam esta e outras escolas do Estado como ação política que visava à melhoria no ensino e na própria estrutura das instituições.

Após as leituras dramáticas, já no começo de 2016, voltamos àquele material e nos demos conta de suas falhas, até mesmo de sua ingenuidade ao abordar o tema do genocídio da população negra. Nosso real desejo era relacionar o caso de Stinney com tantos outros que ocorrem aqui no Brasil - daí o nome, "Alcolu é aqui!" - para tentar dar mais atenção para os altíssimos índices de homicídio contra a população negra, em sua maioria tendo o Estado e sua maquinaria como autores, e 
sendo continuamente invisibilizados. Resolvemos, a partir da autocrítica, reestruturar aquele texto e aquela ideia de espetáculo, e, para tal, empreendemos uma pesquisa contínua que envolveu algumas ações, oficinas, performance urbana, conversas e encontros com outros artistas e colaboradores, rumo a uma segunda versão dessa dramaturgia que desse conta, dessa vez, de abordar essa temática tão dolorosa dentro de uma perspectiva política do fazer teatral. E essa tem sido nossa missão desde então.

Crioula: Os homicídios e a violência infringida contra a população negra no Brasil são elementos importantes de investigação para o trabalho do grupo. Gostaríamos que falassem um pouco sobre a questão e sobre os dados que, mesmo alarmantes, parecem não ser suficientes para promover uma grande mobilização social.

Alcolu: A indignação social é seletiva, ou, melhor dizendo, racista. Basta vermos como é o comportamento das pessoas quando uma injustiça é cometida contra um corpo branco e contra um corpo negro e/ou indígena, sobretudo se o corpo branco possuir maior poder aquisitivo e o corpo negro for pobre e periférico Ter que fazer uma comparação como esta já é uma crueldade que a estrutura racista nos impõe. Mas quando observamos com atenção como estas notícias são veiculadas na grande mídia e como é o funcionamento dos tribunais e da Polícia Militar, que nitidamente adotam critérios raciais para suas condenações e execuções, percebemos que as diferenças são gritantes. Neste momento, por exemplo, tomamos conhecimento que Rafael Braga foi condenado a 11 anos de prisão. O caso deste jovem 
é um exemplo concreto da legitimação do racismo por instituições e instrumentos oficiais. Ele foi o único condenado preso no contexto das manifestações de junho de 2013 em razão do porte de Pinho Sol e estava há um mês cumprindo regime aberto quando foi preso novamente, em janeiro do ano passado, desta vez acusado de tráfico de drogas por estar, supostamente, com 0,6 g de maconha e 9,3 g de cocaína. O juiz preferiu levar em consideração apenas a versão da polícia e ignorou o fato do Rafael alegar que o material foi implantado por policiais, assim como o depoimento de uma testemunha. É um absurdo. Esta é a questão urgente do Brasil, porque todas estas crises políticas e retrocessos de que tanto falam hoje são fundados historicamente pelas relações de raça, gênero e classe. Indo mais afundo, percebemos que tanto o mito da democracia racial, quanto o próprio genocídio da população negra, foram alicerces de um projeto maior que tinha como objetivo branquear a população brasileira. Ou seja, o extermínio, a exclusão, o encarceramento em massa, a marginalização dos negros e da cultura afro-brasileira não se deu por acaso. Como consequência, temos uma sociedade que ensina as pessoas a não admitir e não se responsabilizar pela sua discriminação racial, tampouco abrir mão de privilégios. É preciso reverter e/ou pensar formas de como reverter com urgência este ideário racista brasileiro, para que estas violências não aconteçam mais. É preciso lembrar que organizações como as Mães de Maio, Reaja ou Será Morta, Reaja ou Será Morto, Comitê Contra o Genocídio da Juventude Negra, e tantos outros e outras militantes, ativistas, organizações sociais e coletivos estão nessa luta há anos, trazendo contribuições significativas. Mas ainda há muito a ser feito! 


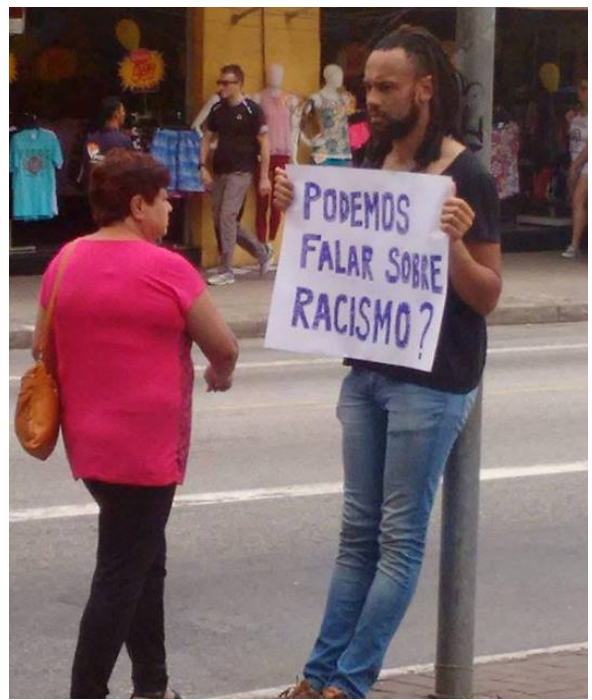

Performance Urbana "Podemos falar sobre racismo?"

Crioula: O grupo apresenta uma compreensão ampla de processo de pesquisa, composição de espetáculo e intervenção social. Gostaríamos que falassem um pouco sobre os elementos dessa composição múltipla que envolve investigação de linguagem, conscientização, mobilização social, criação teatral e uma atuação que se propõe interventiva dentro da sociedade na qual atuam.

Alcolu: Desde o início, imaginamos que seria importante desenvolver uma pesquisa artística que,de dentro do processo criativo, pudesse dialogar e trocar experiências acerca do racismo com a população. Nesse sentido, entendemos que desenvolver oficinas teatrais gratuitas, realizar performances urbanas e criar uma plataforma online de compartilhamento e mapeamento de casos de racismo seria nossa forma de alcançar as pessoas. Paralelamente a estas ações, fizemos 
estudos para a elaboração de um novo texto teatral, e as coisas foram se retroalimentando. Nesse percurso vivemos várias crises, chegando em determinado momento a colocar em xeque a efetividade do teatro para dar conta de debater uma questão tão perversa como esta: o racismo. Ficamos alguns meses pensando em alternativas que não fossem necessariamente vinculadas a elaboração de uma dramaturgia como um objetivo a ser alcançado. Essas crises foram um pouco o resultado da pretensão de dar conta de debater a problemática do racismo através de nossas expressões artísticas, e também pela sensação insuportável de insuficiência diante deste tema. Foi preciso buscar entre nós um entendimento coletivo, um equilíbrio entre nossas vontades, nossa indignação e o nosso teatro. Depois de quase um ano de projeto, resolvemos retomar a ideia de criar uma peça e nos voltamos à tarefa de construir e compreender quem são nossas personagens e de que maneira elas se relacionam com a nossa problemática.

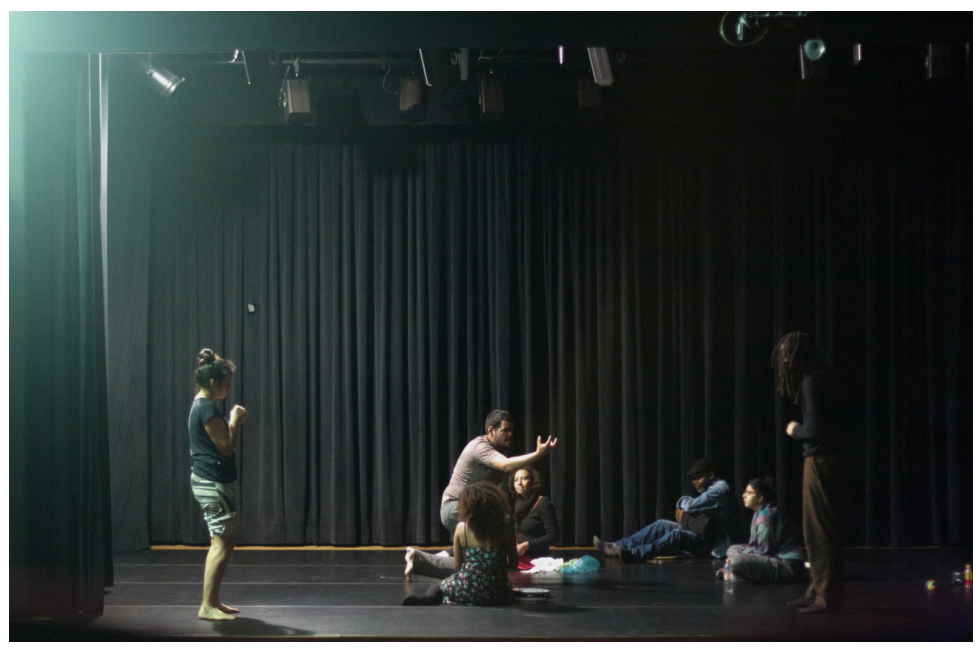

Oficina de atuação (foto: Jere Nunes) 
Crioula: Por que o teatro? Quais entendem ser as potencialidades sociais e políticas dessa manifestação artística?

Alcolu: Escolhemos o teatro para nossas vidas como forma de nos manifestarmos e nos expressamos artisticamente. $O$ teatro é a arte do "aqui e agora", e ele consegue despertar através de infinitas maneiras, diversos sentimentos que nos proporcionam o encontro com nós mesmos, com o outro e com o mundo em que vivemos. Por isso acreditamos que o fazer teatral já é político, por conter nele diferentes corpos expostos e em risco, que se expressam a partir do que são e de suas inquietações. Não é à toa que o teatro sempre foi visto por regimes totalitários como uma ameaça e, ao mesmo tempo, instrumento de manutenção do poder, justamente por essa capacidade de despertar sentimentos nas pessoas, de ser um estímulo para promover mudanças políticas e sociais.

Crioula: Como definiriam o teatro que fazem? Quais as influências teatrais e as referências teóricas e/ou literárias do grupo? Para o grupo, quais foram os dramaturgos que melhor souberam transpor para os palcos as questões sociais?

Alcolu: Bertold Brecht continua sendo a grande referência para um teatro que se propõe a trazer para a cena questões sociais sem a ingenuidade de um herói burguês que tire do público sua possibilidade de agir diante das injustiças do mundo - basta tomar como exemplo o clássico "A Santa Joana dos Matadouros". Na esteira do teatro épico brechtiano, Erwin Piscator e seu teatro-documentário também nos influencia- 
ram bastante com a ideia de trazer para a cena documentos reais, não-ficcionalizados, método que buscamos empregar na compilação e exposição de notícias que denunciam a morte de jovens negras e negros pelas mãos do Estado. Bernard Marie Koltès é um autor sobre o qual nós nos debruçaremos a seguir (a peça "Combate de negro e de cães" será um de nossos materiais de estudos futuros). Grupos contemporâneos como a Companhia do Latão, a Kiwi Companhia de Teatro, a Companhia Brasileira de Teatro, o Núcleo Bartolomeu de Depoimentos, Coletivo Negro e Os Crespos também são artistas da cena cujo trabalho acompanhamos com atenção e admiração e que tanto nos influenciam. Outros materiais, já referentes à performance, ao audiovisual ou à teoria artística, nos serviram de fonte, como por exemplo o "Programa Perfomativo: o corpo em experiência", da performer Eleonora Fabião; "A Estrutura da Notícia", de Roland Barthes; "O Genocídio do Negro Brasileiro", de Abdias Nascimento; "Os Perigos de uma história única", de Chimamanda Adichie; o filme "Selma: uma luta pela igualdade", de Ava DuVernay, entre outros. Nosso teatro ainda está em formação: é difícil classificá-lo de forma estanque, visto que ele ainda sequer se concretizou de maneira fortuita. Mas é possível dizer que ele versa sobre a desigualdade, sobre as injustiças, que ele busca criar um espaço de debate público sobre questões que nos angustiam e que ele quer convidar o público, de maneira sincera e simples, a refletir conosco e, também conosco, pensar em maneiras de revolucionar o estrato social. 
Crioula: O grupo propõe oficinas abertas ao público e espaços de formação de novos atores/pesquisadores. Gostaríamos que falassem um pouco dessa proposta, da comunidade onde atuam e da composição do grupo. Quais os atores envolvidos com o processo inicial de composição do projeto e quais as novas configurações do grupo a partir das oficinas e espaços de formação propostos?

Alcolu: Desde o início, nossas atividades foram centralizadas no bairro da Vila Formosa, zona leste da capital, junto às instalações do Teatro Zanoni Ferrite, no Centro Cultural Vila Formosa. Lá realizamos nossas duas oficinas - de dramaturgia e de atuação - bem como nossa performance urbana, "Podemos falar sobre racismo?". Inicialmente, nossa expectativa era compor junto aos jovens moradores do bairro um amplo grupo de pesquisa, intervenção e ação cênica, mas encontramos alguma dificuldade em conseguir acessá-los, seja por nossa inexperiência - afinal, somos um grupo iniciante - seja pela lógica do bairro, descentralizado, residencial, de classe média, incrustrado em um limite geográfico que pode alça-lo à condição de periférico sem que ele o seja socialmente falando. Passamos por um período de elaboração e pesquisa interna, a partir de um processo de epicização de nós mesmos, onde buscamos investigar em perspectiva histórica quem éramos nós, de onde vínhamos, de onde vinha a nossa família. Finalmente voltamos à Vila Formosa e ao Zanoni Ferrite para apresentar, no começo de 2017, a leitura dramática de "Alcolu é aqui! - Materiais", compilação dos textos que foram escritos durante essa parte do processo. Foi nessa altura que se somou ao nosso coletivo a atriz e produtora Ellen de Paula, 
completando o nosso time de artistas de maneira irrevogável. Também temos parceiros de estrada, como o artista gráfico Edson Ikê, que criou nossa identidade visual, o Estúdio Fante, na criação do site, o Coletivo Sobre.Olhar, no registro audiovisual das atividades, a atriz e musicista Manuella Alves e a sonoplasta e também musicista Jéssica Melo.

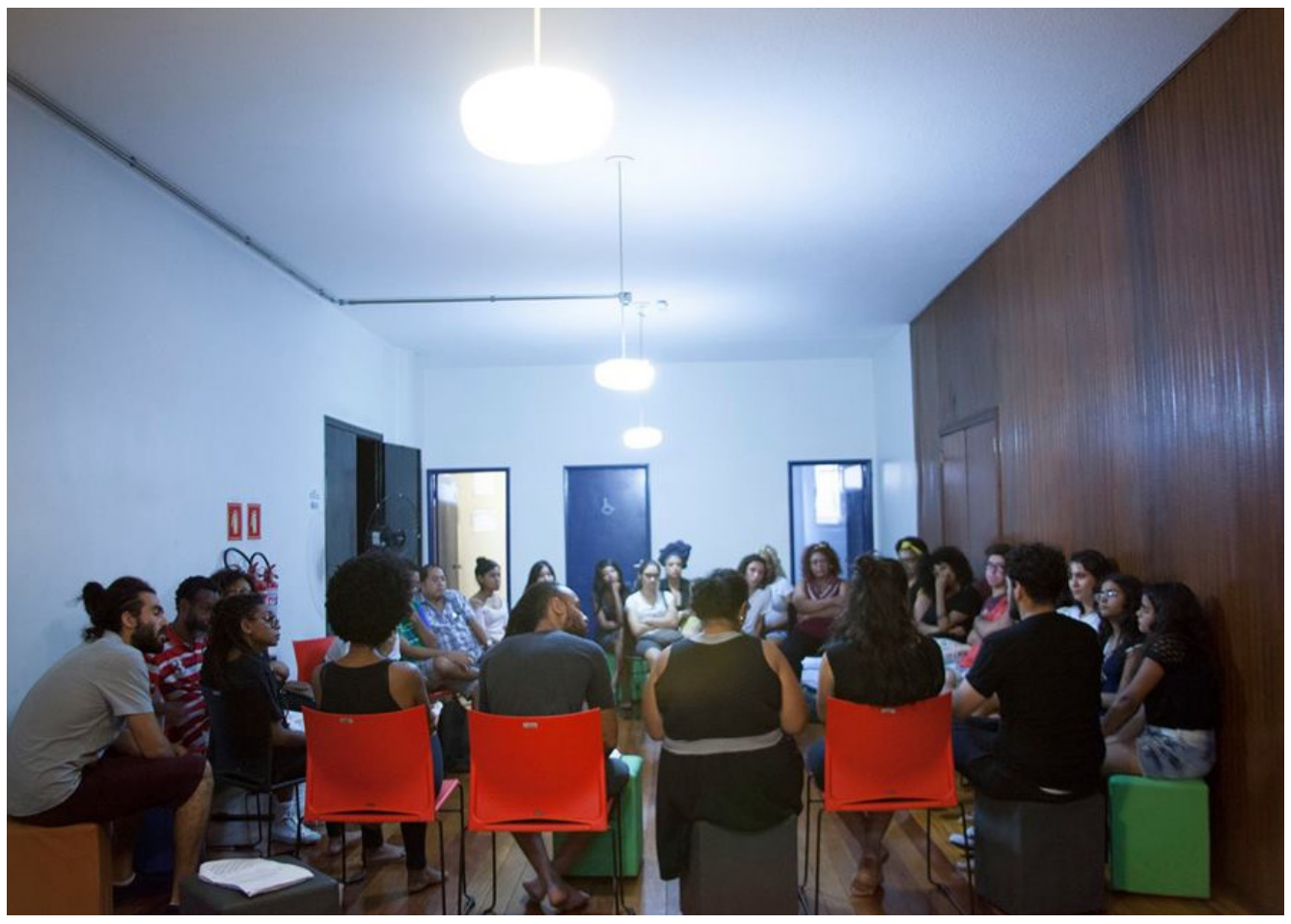

Bate-papo após leitura dramática (foto: Jere Nunes)

Crioula: O grupo propõe um mapeamento qualitativo de casos de racismo, assassinato e tensão racial na cidade de São Paulo. Como surgiu a ideia do mapa e como foi possível viabilizá-la? O mapa segue disponível para que sejam registrados 
relatos. Como fomentam o uso da ferramenta e quanto tempo ela ficará disponível para que os dados sejam alimentados e para que o mapa seja consultado?

Alcolu: A ideia do mapeamento de relatos de racismo surgiu a fim de, para além de ampliar uma memória de resistência coletiva, termos conhecimento público de casos que não sejam apenas através das seletivas notícias de veículos de comunicação. Nós não inventamos isso. Existem diferentes plataformas, páginas em redes sociais e blogs que, antes de nós, fizeram algo parecido. Nosso intuito é somar forças. Esta plataforma online segue disponível por tempo indeterminado e lá qualquer pessoa que sofre com discriminação racial pode fazer relatos e qualquer pessoa pode ter acesso às histórias registradas e mapeadas ali, não só em São Paulo, mas também em outras regiões do Brasil. Os responsáveis pela criação do site foram o Estúdio Fante em parceria com o Edson Ikê. Nós apenas demos algumas referências e indicações. Quando o site ficou pronto, fizemos uma grande divulgação nas redes sociais e tivemos adesão de diversos portais que tem como tema o racismo e a cultura afro-brasileira, e isso ajudou a fazer com que as pessoas tomassem conhecimento. Em seguida, fomos convidado pela ONG "Casa do Zezinho", no Capão Redondo, para conversar com as turmas do curso de Educação, Arte e Tecnologia sobre a origem do mesmo e as possibilidades de utilização da plataforma digital para partiIhar relatos de racismo. Hoje, fomentamos o uso da ferramenta compartilhando relatos em nossa página do Facebook. 
REVISTA CRIOULA N ${ }^{\circ} 19-1^{\circ}$ SEMESTRE/2017

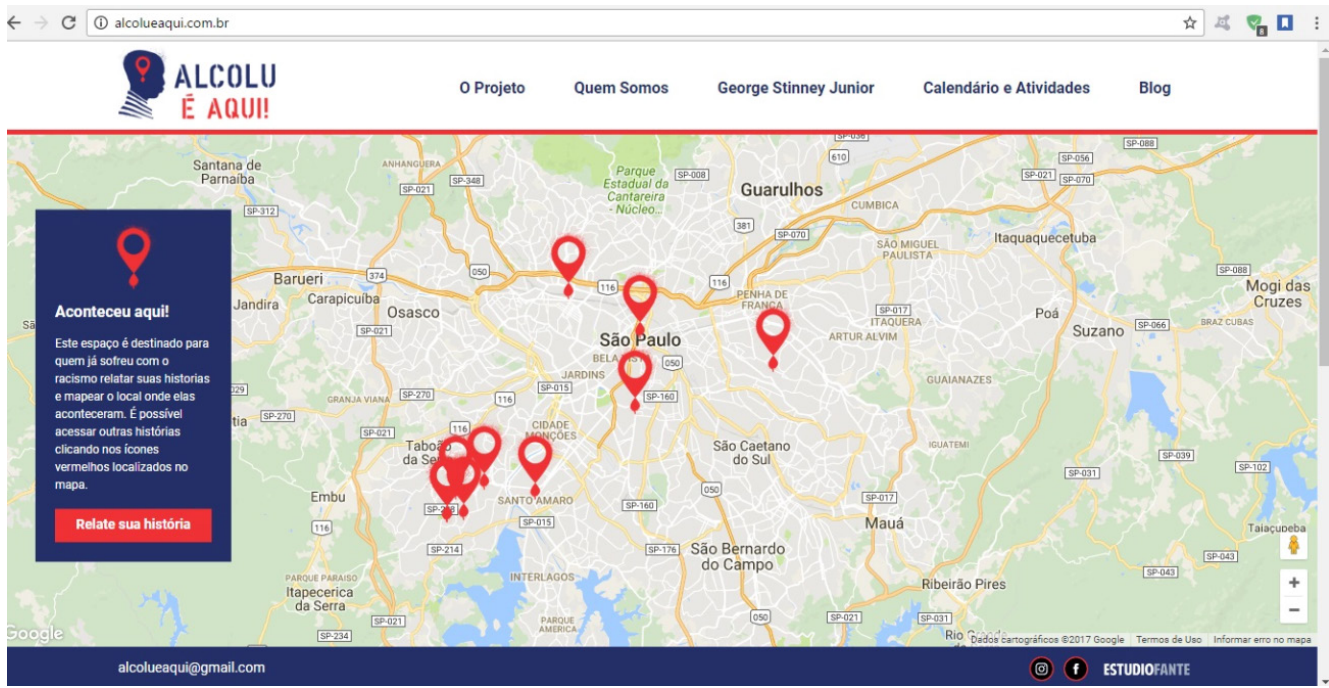

Plataforma online de relatos e mapeamento de racismo - criação de Estúdio Fante

Crioula: O grupo propõe ainda investigações poéticas do território urbano. Como é esse processo e como ele se interliga ao mapeamento da plataforma virtual elaborada dentro do projeto?

Alcolu: Esta investigação teve início através da criação da performance urbana.Nesta experimentação, os performers se posicionam nos mais diversos lugares do espaço público, como ruas, praças, pontos de ônibus, dentre outros espaços, com um cartaz que contém escrito em letras garrafais a seguinte pergunta: "Podemos falar sobre racismo?". A expectativa é de que esta provocação resulte em uma conversa sobre racismo, bem como na percepção dos diversos afetos e reações que a temática instaura nas pessoas que circulam na rua. Inspiramo-nos numa ação chamada "Converso sobre qualquer assunto", da artista Eleonora Fabião. Nossa perfor- 
mance surgiu de questionamentos internos dado ao fato de que debates sobre autoria de narrativas estarem cada vez mais disputados. Como nosso grupo é composto por homens e mulheres negrxs, não-negrxs e brancxs - e entendendo de antemão que é necessário que todas as pessoas se posicionem contra o racismo - interessou-nos problematizar estes diferentes 'lugares de fala para buscarmos compreensão sobre o que isso implica no sentido de privilégios, legitimidade e os pontos de vistas que se abrem a partir da experiência que estes diferentes corpos carregam. Levamos essa questão para as ruas por acreditarmos que é importante que este debate seja público.Conversamos com jovens, adultos, idosos de diferentes raças, gêneros e classes e fomos percebendo que esta pergunta é muito mais ampla do que imaginávamos.

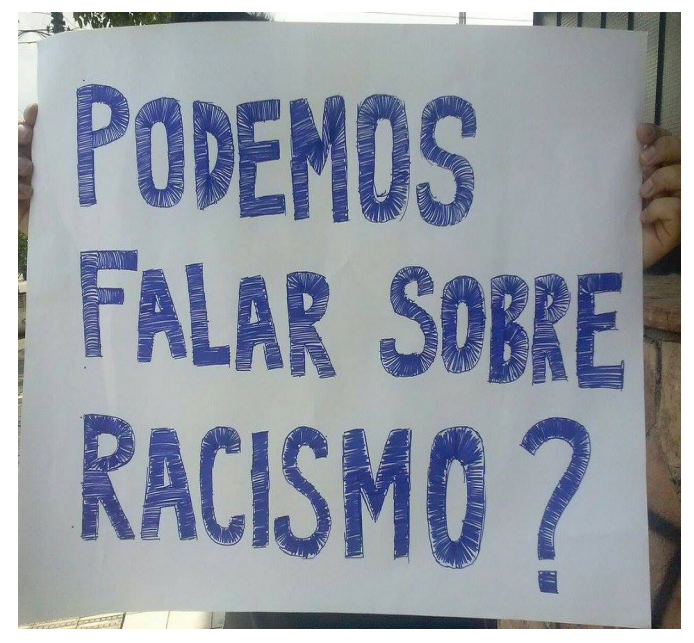

Performance Urbana "Podemos falar sobre racismo?" 
Crioula: Para que o trabalho de oficinas, diálogo com a comunidade e pesquisa fossem realizados, que estratégias foram utilizadas para divulgar, inicialmente, as ações?

Alcolu: Utilizamos as redes sociais (nossa página no Facebook, sobretudo), alguns portais online e o próprio espaço do Teatro Zanoni Ferrite, onde acontecia o Projeto Vocacional de Teatro e de Dança para divulgar as nossas ações.

Crioula: De que forma as histórias de violência racista foram utilizadas como elemento para o processo de criação e reinvenção teatral do grupo?

Alcolu: Este é um dos aspectos delicados do projeto. Em dado momento, percebemos ser ilegítimo nos apropriar materialmente dos relatos de racismo coletados em nosso site ou em nossas experiências diretas com o público. Nossa tentativa tem sido, desde que chegamos a essa conclusão, de ficcionalizar situações que dêem conta de expor as contradições sociais decorrentes do racismo, formulando, para isso, personagens que debatem com esta temática e que tentam lidar com ela movidos cada um por sua condição social e racial. É daí que tiraremos nossa história e nosso futuro espetáculo.

Crioula: O grupo recebe ou recebeu algum tipo de apoio financeiro para manutenção das atividades? Quais? Como fazer para manter vivo e atuante um teatro de resistência e denúncia?

Alcolu: Nosso projeto foi contemplado pela edição 2016 do Programa de Valorização de Iniciativas Culturais - VAI, da Secretaria de Cultura da cidade de São Paulo. Este é um dos 
editais mais importantes da cidade, pois possibilita o fomento à cultura de jovens artistas, grupos e coletivos em regiões periféricas e descentralizadas. Recebemos apoio financeiro do VAl até o mês de fevereiro - quando terminou nosso cronograma. Desde então, continuamos o projeto sem financiamento, mas nosso objetivo é conseguir apoio para realizar a montagem da peça. Este ano, com a chegada da nova gestão da Prefeitura, foram congelados mais de $43 \%$ do orçamento destinado à cultura da cidade, o que inevitavelmente prejudicou diversos projetos e leis de fomento, como Fomento à Dança e ao Teatro, Programa Vocacional e PIÁ, o próprio VAI, e tantos outros. Somos contra o congelamento, pois o orçamento destinado à cultura já era muito baixo, ou seja, fica evidente que as atividades culturais continuadas mais do que não serem prioridades, não estão sendo levadas a sério pela atual gestão, e sabemos quem está sendo mais prejudicados. Esta atual conjuntura política dificulta muito o nosso trabalho, mas, por outro lado, é importante nos perguntarmos: em que momento na história do Brasil foi fácil o 'fazer teatral' para pessoas como nós? Talvez não exista uma resposta de como manter vivo o teatro que queremos fazer, pois este teatro sempre esteve em risco e são justamente estas questões a respeito de sua existência que nos apavora, mas também nos move. Enquanto um grupo novo, nós aprendemos a resistir com artistas, grupos, companhias e coletivos que fazem isso antes nós. 
Crioula: O grupo já fechou o espetáculo "Alcolu é aqui"? Em que pé está o processo? Quais os próximos desdobramentos? Alcolu:No mês de fevereiro realizamos uma leitura dramática aberta ao público de parte dos materiais que irão compor a nossa peça, seguida de um bate-papo. A atividade aconteceu no Centro Cultural Vila Formosa, e serviu para termos uma troca significativa de tudo que fizemos durante o ano de 2016. Agora nós estamos no processo de continuidade de estudos de alguns materiais já programados, finalização da dramaturgia e busca por apoios financeiros para iniciar a montagem. Esperamos estrear a peça no primeiro semestre de 2018.

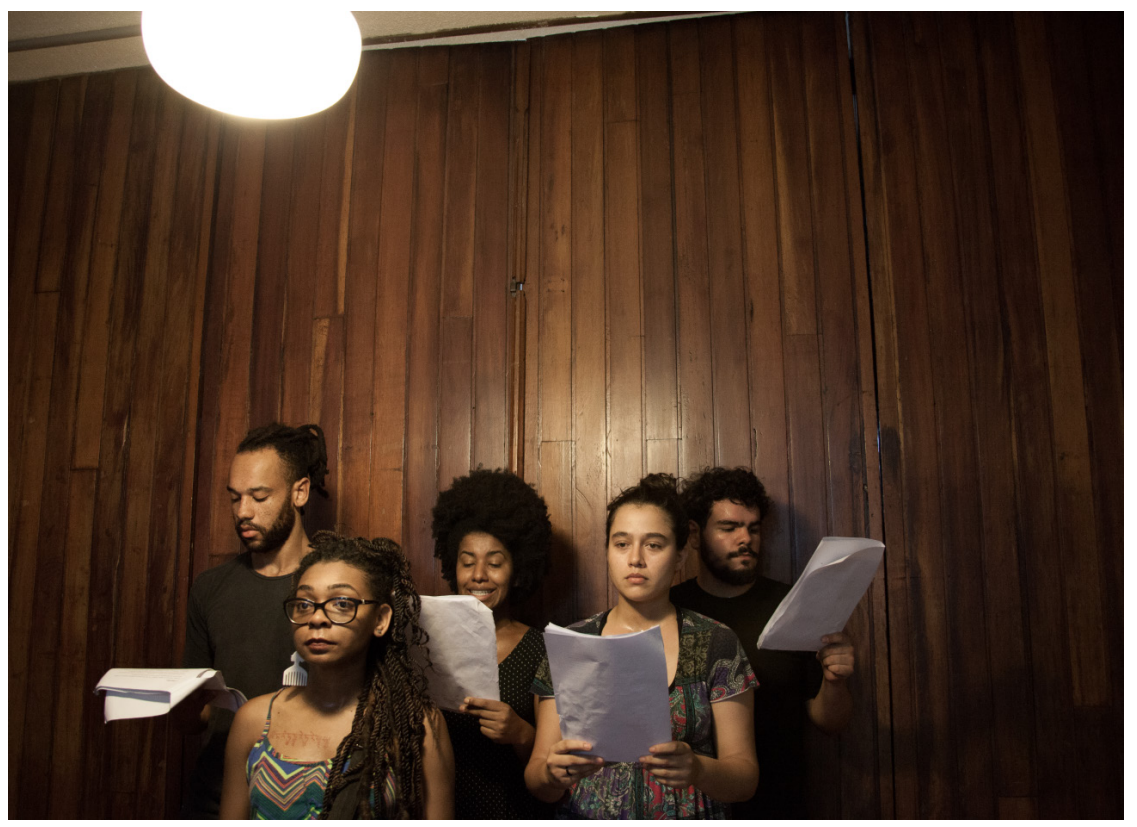

Leitura dramática (foto: Jere Nunes)

Submissão: 2017-05-13

Aceite: 2017-05-13 